Geopolítica(s) Revista de estudios sobre espacio y poder ISSN: 2172-3958

https://dx.doi.org/10.5209/geop.72012

\title{
Geometrías de poder y procesos de patrimonialización: políticas
} [multi]escalares de significación

Tuuli Lähdesmäki, Suzie Thomas y Yujie Zhu (2019) Politics of Scale: New Directions in Critical Heritage Studies. Nueva York, Oxford: Berghahn Books. ISBN: 978-1-78920-016-4.

El libro editado por Tuuli Lähdesmäki, Suzie Thomas y Yujie Zhu, recoge los trabajos de una red de investigadores e investigadoras que, desde diferentes latitudes, se inscriben en el giro epistemológico que ha tenido lugar dentro del campo de los estudios del patrimonio. Fraguado al calor de los cambios acaecidos en las últimas décadas (incremento de las redes transnacionales, flujos globales, hibridez cultural, conflictos socio-ambientales, etc.), y con una clara vocación transdisciplinar, este trabajo colectivo abraza múltiples enfoques y metodologías, a la vez que incorpora gran parte del acervo teórico del giro espacial y cultural. Así, desde una perspectiva eminentemente crítica y un compromiso político explícito, el abordaje holístico de cuestiones otrora naturalizadas o soslayadas en debates disciplinares estancos, les permite (de)construir y analizar su complejo objeto de estudio, a saber: la relación existente entre los procesos de "patrimonialización" y las políticas de escala. Además, para develar las diferentes formas en las que las relaciones de poder [multi]escalares atraviesan los procesos y prácticas por los que se identifica, representa y disputa el significado mismo del Patrimonio cultural ${ }^{1}$, parten del cuestionamiento de: 1) las geometrías de poder ${ }^{2}$; 2) las "grandes narrativas" universalizadoras 3 ; y 3 ) la marcada impronta histórica (nacionalista, imperialista y colonial) de los discursos hegemónicos de la Modernidad occidental-eurocentrada; identificando no sólo la temporalidad de estos múltiples y simultáneos procesos, sino también su intrínseca y dinámica espacialidad.

El compendio de trabajos ante el que nos encontramos, a su vez, se ha articulado en torno a tres grandes cuerpos de análisis. Una primera parte, en la que podemos encontrar el debate conceptual en torno a la "escala" como tropo, así como a su pertinencia como herramienta analítica, teórica y metodológica; una segunda, en la que se abordan diferentes procesos de construcción y producción de patrimonio

1 Patrimonio cultural material y simbólico, tangible e intangible. La concepción de la que parten los autores gira en torno a la multiplicidad y complejidad de objetos, lugares, valores, memorias, emociones e identidades (p.2) que constituyen, de forma relacional y cambiante en tiempo y espacio, el patrimonio cultural.

2 Concepto acuñado por Doreen Massey para reafirmar las relaciones espacialmente asimétricas de poder, de acuerdo a la relación coconstutiva de lo espacial y lo social; lo espacial y lo político; el espacio y el poder.

3 Del mismo modo en el que se habría traducido el giro de los enfoques postestructuralistas y postmodernos. 
cultural desde el análisis de diferentes instituciones y actores, así como de las geografias y políticas escalares de la gobernanza patrimonial; y por último, una tercera, en la que se identifican acciones y prácticas concretas de patrimonialización en una arena disputada por diferentes agentes. Si bien esta división de la obra resulta pedagógicamente útil para acompañar al lector/a, lo cierto es que no se puede entender una parte sin la otra. La lectura transversal de cada uno de los trabajos presentados, de hecho, será lo que nos permita ahondar un poco más en este novedoso campo de estudios del patrimonio, sobre todo a la luz de los descubrimientos que cada autor/a nos brinda con respecto a sus casos de estudio. Sin obviar esta cuestión y consciente de que una reseña integradora negaría la especificidad y riqueza de cada uno de estos trabajos, se intentará presentar una lectura particularizada de cada uno de los ejes indicados supra, para poder recoger algunas de las premisas de partida, debates y resultados que permitirán, en última instancia, esbozar una suerte de reflexión crítica en torno a los debates contemporáneos sobre la escala.

De este modo, a través de los tres trabajos de Yujie Zhu, Tuuli Lähdesmäki y Katja Mäkinen, Rhiannon Bettivia y Elizabeth Stainforth, podemos observar cómo el giro espacial y el legado de la discusión teórica y conceptual de la geografía política en torno a la escala han sido incorporados a los estudios críticos del patrimonio. El alineamiento con una conceptualización de la escala como proceso socio-espacial de significación y producción fluida, relacional y múltiple, hace que las fronteras de, y entre, estas configuraciones de poder - antes comprendidas como categorías materiales pre-dadas, bien delimitadas y estancas-, se entiendan ahora como simultáneas y co-constitutivas. Del mismo modo que se replantean el alcance teórico y metodológico de la escala como concepto y herramienta da análisis, abordan la idoneidad de su aplicación a las nuevas formas de entender el «patrimonio cultural». Esto es, más que como un objeto concreto, incuestionable e inmutable, el patrimonio se entendería como un constructo contingente que resulta de un proceso abierto de significación — proceso de "patrimonialización" cado por complejas relaciones entre actores, contextos, recursos, discursos, prácticas y representaciones que se dan forma en el dialógico y multiescalar juego político que nos dibujan con sus estudios de caso.

Así, mediante la exposición del caso de la antigua ciudad de Lijiang, en China, — declarada Patrimonio de la Humanidad por la UNESCO en 1997-, Zhu nos muestra la importancia de la escala estatal en el reordenamiento y gestión del patrimonio cultural. Una política cultural centralizada y una gobernanza multi-nivel y multi-actor eminentemente jerárquica, hacen que el debate en torno a la escala y las políticas escalares se torne especialmente relevante para entender los modos en los que se deciden e implementan los procedimientos administrativos "desde arriba" -top-down y downscaling - , reduciendo los márgenes de acción de las comunidades locales. Esto es, mediante la adopción de los parámetros de la UNESCO y la integración del discurso occidental dominante, el sistema de gestión del patrimonio en China habría articulado diferentes niveles de administración en una política

4 Desde finales de los 2000, se habría venido incorporando a la literatura (geografía política, geografía cultural, antropología, etc.) este concepto de "patrimonialización" (heritagization o heritage-ization) que da buena cuenta de la nueva dirección adoptada dentro de los estudios sobre patrimonio. Ver M. Lois y H. Cairo: Heritage-ized Places and Spatial Stories: B/Ordering Practices at the Spanish-Portuguese Raya/Raia. Territory,

Politics, Governance, 3(3), 2015, 321-343. 
escalar vertical: desde la escala internacional a la nacional y, de ahí, a los niveles más bajos (p.25). Ahora bien, esto no implica que lo local esté desmovilizado. De hecho, y a pesar de la institucionalización de esta política escalar, Zhu también nos descubre un escenario de resistencias locales que, "desde abajo" (upscaling), han hecho frente a la abrupta transformación (turistificación, gentrificación, desplazamientos) que ha experimentado Lijiang desde que fuera incorporada al inventario del patrimonio global.

El trabajo de Lähdesmäki y Mäkinen, por su parte, nos trae un debate que atraviesa los cimientos mismos del proyecto de integración europeo. Ante el auge de los populismos de derecha, el escepticismo anti-europeista y los nuevos nacionalismos (p.36) los autores nos presentan una reflexión en torno a la relación del patrimonio y la escala desde el papel de la historia, la memoria, la cultura y las narrativas de lo común. De acuerdo a éstos, un discurso político multiescalar que abrace el patrimonio cultural como vehículo para significar la "europeidad" e imaginar la comunidad política europea - sin negar la pluralidad, diversidad y especificidad de lo nacional, regional y local—, podría ser una de las vías para impulsar el proyecto de integración desde una política escalar post-, supra- y trans-nacional.

El trabajo de Bettivia y Stainforth, parte del novedoso análisis del patrimonio cultural desde su producción y reproducción en el espacio digital "público". Esto es, cómo el constante proceso de creación y consumo de contenidos culturales en red, puede ser analizado como política escalar a pesar de que, a priori, el espacio digital no pueda delimitarse geográficamente del mismo modo que otros procesos de patrimonialización. Para ello, comparan dos bibliotecas digitales open access que funcionan como recopiladoras de contenidos culturales. En este caso, analizan Europeana, como proyecto supranacional y la Biblioteca Digital Pública de Estados Unidos, como proyecto "nacional", en aras de mostrar la interconectividad escalar (p. 59) de estos proyectos tecnológicos, en su capacidad de garantizar el acceso al patrimonio cultural como bien común.

La segunda parte del volumen, nos introduce los procesos multiescalares de patrimonialización desde el análisis de diferentes "geografías de la gobernanza" (p.81). Así, Butland introduce el caso de Angkor (Camboya) para mostrarnos las porosas fronteras de las diferentes escalas que intervienen en el proceso de significación del patrimonio cultural. Desde que Angkor fuera declarada Patrimonio de la Humanidad en 1992, múltiples actores (agencias internacionales, gobierno y administración nacional, expertos y profesionales, etc.) a diferentes escalas, han dado cuenta de la multi-dimensionalidad de los procesos de creación y atribución de valor cultural a nivel local, nacional y global. De este modo, y teniendo en cuenta que las agendas política y económica tienden a reificar el patrimonio como espacio eminentemente productivo (p.76), la autora nos invita a reflexionar acerca de los procesos de formalización de fronteras entre escalas de acción y lo que suponen para las prácticas y valores de las poblaciones locales.

Por su parte, Lois aborda las políticas escalares de patrimonialización desde el estudio de los programas de cooperación transfronteriza de la Unión Europea. A partir de dos proyectos de cooperación implementados en la frontera hispanoportuguesa (BIN-SAL y la Eco-raya), nos ofrece un análisis de las políticas de patrimonialización fronteriza que no sólo van más allá del Estado-nación como agente y escala preeminente, sino que también trascienden la normalizada escala 
regional de las políticas de integración del proyecto europeo. De este modo, aún cuando la mirada sigue siendo eminentemente multiescalar, el trabajo hace énfasis en la reafirmación de la importancia de los procesos y actores locales. Poniendo en el centro el alcance discursivo y performativo de las narrativas y prácticas transfronterizas, la autora nos muestra cómo estos proyectos de cooperación, se convierten en espacios de contestación y conflicto; pero también de coexistencia y encuentro; interpenetración y sincretismo (pp.91-92). En definitiva, en paradójicos espacios intermedios de movilización de otras espacialidades de frontera.

Como cierre de este eje, Kähkönen y Lähdesmäki, proponen un análisis amplio y comprehensivo de las políticas de patrimonio cultural mediante la adopción de una perspectiva ambientalista. Para ello, parten de una concepción del patrimonio cultural muy vinculada a la racionalidad ecológica del "desarrollo sostenible" como principio rector. Tomando como contexto la progresiva incorporación del concepto de cultural environment en la agenda y políticas de la Unión Europea, pasando por el uso preconizador que previamente hicieron de él los países nórdicos, los autores abordarán la política finlandesa como punto de partida para analizar la relación entre la actividad humana y el medio natural —entendido éste como patrimonio cultural- De este modo, realizan una lectura multiescalar del rol desempeñado por este principio rector en las políticas, planes y programas patrimoniales que lo han incorporado a nivel cotidiano, local, nacional, regional y europeo (p.97), teniendo en cuenta la participación de la sociedad civil —el participatory turn - en los procesos de administración en red.

Una vez introducido el debate en torno al concepto de escala y habiendo abordado la aplicación del mismo a esas geografías diseminadas de gobernanza del patrimonio cultural, en la tercera parte encontramos una análisis pormenorizado de diferentes prácticas de patrimonialización, así como la politización de sus consecuencias en múltiples escalas.

En el primero de los trabajos, podemos encontrar un análisis crítico del patrimonio cultural y, concretamente, de la significación política de las huellas que dejó la presencia alemana en la región Sápmi ${ }^{5}$ (Finlandia) durante su ocupación en la II Guerra Mundial. Así, a partir de la noción de dark heritage, Thomas nos acerca a una revisión de aquel patrimonio cultural que funciona, no sólo como recurso económicamente funcional (fetichización, exotización, turistificación), sino también como detonante y catalizador de emociones, narrativas y memorias eminentemente contestadas - a menudo estrechamente vinculadas con experiencias e historias de un pasado doloroso-. Es justamente a partir del análisis de diferentes actores y prácticas de patrimonialización material (excavaciones, búsqueda, recolección, exposición), desde donde el autor es capaz de mostrar los impactos multiescalares (personales ${ }^{6}$ e institucionales, locales y nacionales), de ese patrimonio cultural politizado y profundamente disputado.

5 En el texto, aparecen los términos "Laponia finlandesa" y "Sápmi”. En la reseña se adopta la denominación Sápmi como posicionamiento consciente de acuerdo al carácter eminentemente contestado del topónimo. Además, teniendo en cuenta los supuestos críticos del autor en su análisis de la exotizada otredad periférica de los pueblos indígenas de la región, parecería desacertado utilizar una denominación que los mismos pueblos indígenas consideran impuesta por el Estado.

6 El autor remarca las fronteras entre el ámbito de lo público y de lo privado, equiparando éste último con "lo personal". Empero, en tanto en cuanto el eje del volumen gira en torno a las políticas de escala, se ha optado por enfatizar una lectura politizada y pública de lo personal. 
Del análisis de las prácticas que rodean este controvertido patrimonio material, pasamos al trabajo de Buljubašić y Lähdesmäki, centrado en la estrecha relación que existe entre el patrimonio cultural inmaterial, las prácticas de los proyectos de marca-país y los discursos de marketing turístico. Así, y partiendo del impacto del patrimonio cultural en las acciones y prácticas concretas de la gente (p.126), los autores abordan el papel de la música Klapa (Croacia) como representación cultural y marcador de múltiples identidades. Entre las conclusiones que arrojan, señalan que, más allá de los efectos que tiene la movilización y popularización de este tipo de patrimonio como atractivo turístico y recurso económico, es necesario entender el calado de los discursos y prácticas de patrimonialización en términos de representación cultural y articulación del imaginario social. En el caso del Klapa, estas prácticas vinculadas a proyectos de construcción nacional y fomento del turismo, han dejado entrever los ambiguos giros discursivos que se encuentran presentes en los procesos escalares de demarcación de fronteras e identificación -lo dálmata, lo croata, lo balcánico, lo mediterráneo, lo europeo, lo occidental—.

El trabajo de Windover y Grant, por su parte, subraya el importante papel que desempañan las geografías mediáticas en los procesos multiescalares de patrimonialización y construcción de identidad política. Centrándose en el caso de Terranova — que en 1949 pasó de ser dominio británico a territorio canadiense-, proponen un análisis de la relación entre proyectos políticos-nacionales y estructuras patrimoniales de acuerdo a la espacialidad de las prácticas de radiodifusión y a la capacidad que tienen éstas de articular la opinión pública — enmarcando cotidianamente las imágenes, sentidos valores de los "artefactos" (p.140) culturales, espaciales e identitarios-.

Por último, en el epílogo, Kuutma realiza una lectura transversal de esa suerte de diálogo establecido entre autores/as, haciendo una síntesis de las principales premisas y debates que atravesaban a cada una de las contribuciones. Como ya se adelantó, ninguna de las partes en las que se dividía este libro podía abordarse por separado. Teniendo en cuenta que el objeto siempre fue comprender la política escalar de los procesos de patrimonialización y generar planteamientos propositivos en este ámbito de identificación y gestión del patrimonio cultural material y simbólico, el autor destaca la importancia de la estructuración escalar jerárquica, de los regímenes internacionales del patrimonio y los procesos de hegemonización de valores de los que participan organismos internacionales, gobiernos y administraciones, museos, centros de investigación, etc. De este modo, esas geografías de la gobernanza se revelan asimétricas, no sólo en los procesos de identificación y significación del patrimonio, sino en su gestión e instrumentalización. Si algo se puede extraer de los trabajos — véase concretamente Zhu, Butland y Buljubašić y Lähdesmäki- es que esos procesos de patrimonialización tienden a ser legitimados e incorporados al discurso de mano de marcadas agendas políticas y económicas. Los procesos de turistificación del patrimonio y la subsecuente significación de éste no sólo como atractivo sino como recurso o motor económico, recuerdan, según el autor, a los discursos civilizatorios de la modernidad (p.167). A la transferencia de esa receta modernizante de comunidad política territorialmente centralizada y crecimiento económico - visible en ese principio de funcionalidad y productividad que entiende el patrimonio cultural como vía de modernización y desarrollo socio-económico-, se suma la circulación de esos supuestos "valores 
culturales universales" de un mundo a imagen de Occidente. Estas geometrías de poder que tanto han cuestionado los estudios postcoloniales y decoloniales, son las que precisamente permiten entender esa pugna política multiescalar en torno a la significación y la representación ${ }^{7}$, sobre todo si tenemos en cuenta la envergadura del impacto que pueden tener determinados regímenes de control al desplegarse en el espacio de forma descontextualizada - esto es, sin conocimiento situado de los lugares y las gentes directamente relacionadas con el inventario patrimonial-

Sin centrarse en la escala estatal-nacional ${ }^{8}$, lo cierto es que buena parte de las contribuciones también han hecho referencia a la importancia de las narrativas patrimoniales no sólo en los proyectos de construcción de la nación ${ }^{9}$, sino en los procesos de identificación local, regional, transnacional, esto es, en las "políticas de pertenencia" $"$. El carácter eminentemente contingente de estos objetos, lugares, prácticas, valores, identidades, memorias, emociones identificados como patrimonio cultural, de hecho, nos hace entender tanto los procesos de imposición y asimilación, como los de apropiación y coexistencia o los de contradicción y disputa. De hecho, es esta ambigüedad y variabilidad de puntos de encuentro entre actores, discursos y prácticas ${ }^{11}$ lo que permite $-\mathrm{y}$ justifica-, en última instancia, la aplicación de este enfoque multiescalar al análisis de las relaciones de poder que atraviesan las políticas patrimoniales.

Presente también en muchos de los trabajos, el análisis multiescalar de la gobernanza multi-nivel y multi-actor del patrimonio, ha puesto de relieve la brecha entre lo discursivo y lo performativo, lo retórico y lo práctico, sobre todo si se analizan los procesos de patrimonialización vinculados a proyectos implementados "desde arriba". Ya sea desde organismos internacionales como la UNESCO, entidades supranacionales como la Unión Europea o gobiernos nacionales, los discursos incluyentes y políticamente comprometidos corren el riesgo de quedar en papel mojado si se relegan o subordinan las demandas, saberes y prácticas de las comunidades directamente vinculadas — material y simbólicamente - a los respectivos lugares, objetos $\mathrm{y} / \mathrm{o}$ actividades patrimonializados.

A menudo, tal y como nos plantean gran parte de los y las autoras de estos trabajos, lo que se constata es la existencia de un sistema de gestión que, si bien es estructurante en sus efectos - con tendencia a la jerarquización (p.4) - también se encuentra eminentemente contestado desde múltiples y diseminadas escalas de acción. Precisamente, es ese carácter multiescalar de la(s) resistencia(s) lo que permite poner el acento en agentes, estrategias, prácticas y representaciones espa-

7 Véase S. Hall: The Work of Representation, en S. Hall (Ed.), Representation: Cultural Representations and Signifying Practices. Londres, Thousand Oaks, Nueva Delhi / SAGE y The Open University, 1997.

8 El enfoque multiescalar parte también de la superación del nacionalismo metodológico.

9 Para profundizar en esta cuestión, véase B. Anderson: Comunidades imaginadas: reflexiones sobre el origen y la difusión del nacionalismo. México D.F., Fondo de Cultura Económica, 1993; y H. Bhabha: Introducción: narrar la nación, en H. Bhabha (Comp.), Nación y narración: entre la ilusión de una identidad y las diferencias culturales. Buenos Aires, Siglo Veintiuno Editores, 2010.

10 Para entender los términos en los que se propone este concepto, véase N. Yuval-Davis: Belonging and the Politics of Belonging. Patterns of Prejudice, 40(3), 2006, 197-214.

11 Actores, discursos y prácticas oficiales, autorizadas, prescriptivas, institucionalizadas, hegemónicas se encuentran con aquellas subterráneas, alternativas, marginales, periféricas, disonantes dando lugar a nuevas formas y configuraciones de carácter ambiguo, sincrético, híbrido. 
ciales otras. Es más, mediante la identificación de esas "escalas de resistencia"12 presentes en los procesos dialécticos de producción cultural, podemos entender no sólo la variabilidad de sentidos y valores que permean los procesos de patrimonialización, sino también los modos en los que la diferencia, a menudo oposicional, transforma los límites y posibilidades de la acción política. En última instancia, el concepto de escala como proceso ${ }^{13}$ (p.6) que se sostiene en este volumen, permite que en un ejercicio coral -independientemente de los diferentes trabajos, objetos de estudio y escalas analíticas adoptadas en cada uno de ellos_-, sea posible abordar el complejo y dinámico entramado de relaciones socio-espaciales y geometrías de poder que atraviesan los discursos y prácticas de patrimonialización.

Paula Medina García

Departamento de Historia, Teorías y Geografía Políticas

Facultad de Ciencias Políticas y Sociología Universidad Complutense de Madrid Email: paulamed@ucm.es

12 L. A.Staeheli: Empowering political struggle: spaces and scales of resistance. Political Geography, 13(5), 1994, 387-391.

13 Dejando a un lado el debate en torno a qué figuración espacial resulta más idónea para representar la configuración escalar (escalera, muñeca rusa/nesting doll, red, etc.) y la direccionalidad de su movimiento (downscaling,upscaling; top-down, bottom-up). 